\title{
APLICAÇÃO DO MÉTODO DE LEAN MANUFACTURING, POKA-YOKE, COMO MELHORIA NA PRODUÇÃO DE CESTAS DECORATIVAS
}

\author{
Bruno Clímaco Santiago (UFPE) brunosantiago100@gmail.com \\ Maria Tereza Nunes Lira (UFPE) mterezanlira@gmail.com \\ Osmar Veras de Araújo (UFPE) osmarveras@yahoo.com.br
}

\section{Resumo}

Com o avanço da tecnologia e o surgimento da indústria 4.0, onde o fordismo não é mais suficiente para demanda de produção, que passou de uma produção em massa dando lugar a personalização e variação de produtos, o Toyotismo começa a ser mais efetivo e em especial o foco na redução e eliminação de desperdícios. A partir dessa filosofia desenvolveu-se o Lean Manufacturing, que tem como referência o Sistema Toyota de Produção para a produção enxuta. Com a medição e análise dos dados de produção das cestas decorativas feitas de paletas de picolé, através do estudo da produção enxuta uma proposta de melhoria contínua é implementada, através do método Poka-Yoke, onde criou-se um mecanismo a prova de falha, método preventivo, para montagem das peças que formam o produto final por um molde. Com isso o estudo dos tempos foi feito novamente a fim de comparar os procedimentos e comprovar a eficácia do método para padronizar, eliminar os erros e diminuir o tempo gasto em processos que não agregam valor ao produto.

Palavras-Chaves: Toyotismo; Lean; Métodos; Padronização

\section{Introdução}

Desde o final do século XVII e início do século XVIII, fase da revolução industrial, o processo produtivo vem passando por mudanças e avanços ao decorrer dos anos. Produtos que eram produzidos manualmente e artesanalmente, agora dão espaço a máquinas, aglomerado de pessoas, e uma necessidade de produção em grandes escalas, com tempos reduzidos.

Ao final do século XVIII e início do século XIX, surge Frederick Taylor, engenheiro norte americano, considerado o pai da administração científica pois foi um dos primeiros a sistematizar o processo de produção. Taylor visualizava que a partir do momento que otimizasse os movimentos, aliado com a prática de se repetir determinada atividade, conseguiria a diminuição considerável do tempo de execução dessa atividade. 
Taylor buscava, com isso, uma forma de gestão que fizesse com que o trabalhador produzisse mais em menos tempo, sem elevar os custos de produção da empresa. Ele observou que o sistema de gestão da época continha muitas falhas, entre elas: a falta de padronização dos métodos de trabalho, o desconhecimento por parte dos administradores do trabalho dos operários e a forma de remuneração utilizada nas empresas. (PERIARD, 2012).

Em 1903, em seu livro “Administração de Oficinas” Taylor propõe que o estudo deva-se ser racionalizado, por meio do estudo os tempos e dos movimentos. Este estudo, visava a criação e aplicação de uma metodologia que deveria ser utilizada por todos os colaboradores em decorrência da padronização dos métodos, movimentos e ferramentas. Tudo isso com a intenção de eliminar o desperdício dos esforços com movimentos inúteis e melhorar a eficiência e o rendimento.

Através do estudo de tempos e movimentos, é possível criar uma metodologia de produção que integre todas as partes do processo produtivo, inclusive a relação homem-máquina. Segundo Barnes (1977), o presente modelo beneficia o sistema produtivo padronizando-o, adequando o tempo ideal e aperfeiçoando o colaborador com o novo método, alavancando a satisfação de todos envolvidos nas etapas produtivas.

Partindo do princípio da padronização e aperfeiçoamento dos métodos, nasce então o termo lean, traduzido para enxuto. Essa filosofia estrutura e direciona toda execução do processo de forma enxuta, utilizando apenas recursos necessários. Para diminuir o erro operacional e para implantar o sistema lean os processos precisam serem autônomos, com pouca intervenção humana. Partindo deste princípio chega-se ao Poka-Yoke, ferramenta desenvolvida pelo engenheiro da Toyota nos anos 60, Shigeo Shingo. Uma ferramenta de produção enxuta em que se baseia o estudo deste trabalho, a respeito da análise dos tempos e movimentos na produção de cestas decorativas, cujo a matéria prima são paletas de picolé é proposto um método de melhoria.

\section{Referencial teórico}

O Sistema Toyota de Produção (STP) é um sistema de gerenciamento da produção que tem como seu principal objetivo o aumento do lucro através da redução dos custos. Para que a maximização dos lucros seja concretizada, é preciso identificar, mensurar e extinguir as atividades que não agregam valor ao produto. (GHINATO, 1996). 
Ohno (1977) afirma que para que o STP esteja funcionando perfeitamente, o mesmo precisa estar alicerçado por bases sólidas. Essas bases são relacionadas a colinas, ou pilares, sendo eles o Just In Time (JIT - "no momento exato") e o Jidoka.

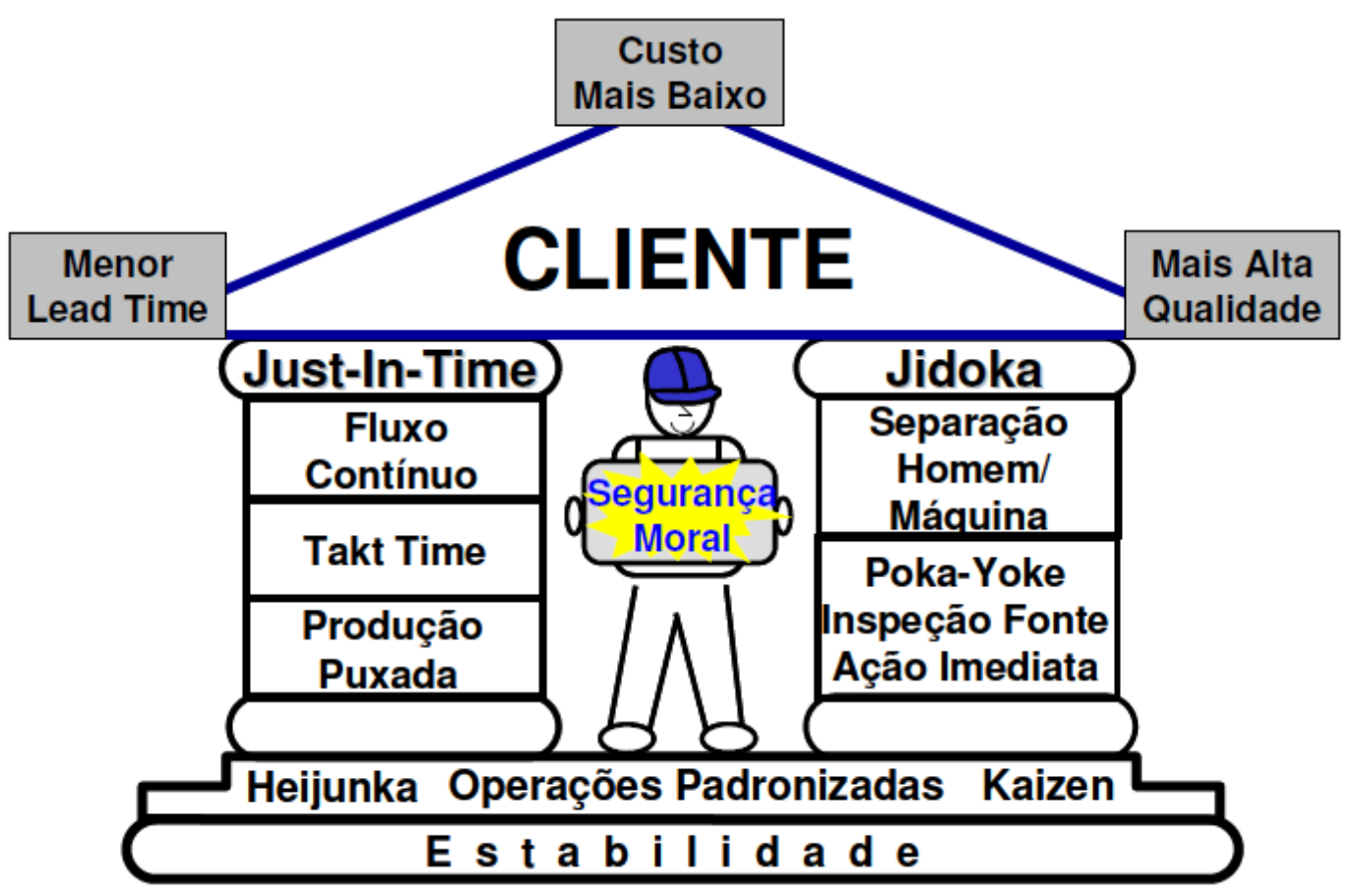

Fonte: Chinato, 1996

Para o STP, a capacidade produtiva de um sistema é medida através da soma do trabalho com as perdas, sendo o trabalho dividido em dois grupos: trabalho efetivo, que agrega valor ao produto, e trabalho adicional que não agrega valor ao produto. Logo o STP tem como visão aumentar a taxa de trabalho efetivo, implicando diretamente na diminuição do trabalho adicional. (OHNO,1997).

Martins (2009) afirma que o Jidoka tem como principal objetivo reduzir ou eliminar a influência humana na realização das atividades, onde busca-se a mecanização para que as operações sejam realizadas sem a necessidade de intervenção humana, oriundo de detecção autônoma com dispositivos de segurança adequados à proteção do operador. Por este motivo, o Poka-Yoke está inserido no Jidoka.

Segundo Shimbun (1988), o Poka-Yoke tem sua origem na Toyota Motors Company, tendo como principal objetivo a eliminação total dos defeitos "zero defeito". No início, foi chamado 
de a "prova de bobos", porém, o termo era ofensivo para com os trabalhadores, por este motivo passou-se a ser chamado de "a prova de falhas". Tinha como principal objetivo a extinção do erro humano, visto como o maior causador de defeitos.

Para Nogueira (2010) existem três tipos de classificação para o Poka-Yoke: métodos de contato; métodos "fixed-value" e métodos "motion-step". Sendo os mecanismos mais utilizados: interruptores, sensores, termômetros, medidores de pressão e temporizadores. Podendo, cada um dos mecanismos citados acima, serem utilizados das mais variadas formas, respeitando a originalidade do processo produtivo.

Segundo Shingo (1996), a aplicação do Poka-Yoke é facilitada quando são respeitadas seis regras básicas, tais como: escolher um processo piloto e fazer uma lista dos erros mais comuns dos operadores; priorizar os erros por ordem de frequência; priorizar os erros por ordem de importância; projetar sistemas Poka-Yoke para impedir os principais erros das duas listas; utilizar Poka-Yoke de controle quando é impossível corrigir o defeito; fazer uma análise de custo-benefício antes de implementar o sistema Poka-Yoke.

Shingo ainda salienta que algumas empresas estão perdendo o foco que o conceito de PokaYoke apresenta. Busca-se a solução dos problemas na construção de ferramentas e métodos altamente complexos, o que gera novas etapas no processo, muitas vezes fugitivas da realidade da organização. Deve-se priorizar o simples, óbvio e prático que agregam nas operações já existentes.

Em uma análise do sistema, Pojasek (1999) conclui que existem sete pontos em que o sistema a prova de falhas é eficiente nas seguintes situações: rotina de uma sequência fixa de operações; fabrico de várias referências; operações de fabrico com especificações claramente definidas; número de parâmetros do processo a controlar reduzido; controle estatístico do processo difícil de implementar ou ineficaz; controle de atributos qualitativos e não quantitativas; rotatividade de pessoal alta e custos de formação elevados.

Pojasek também menciona que o sistema não funciona bem em três situações: processos com cadência de produção muito elevada; processos com autocontrole e cartas de controle aplicadas eficazmente; processos com mudanças mais rápidas do que os dispositivos PokaYoke. 
$\mathrm{Na}$ atualidade um dos recursos mais importantes e mais escassos das organizações é o tempo. Para melhorar a aplicação deste recurso a cronoanálise é uma das melhores ferramentas disponíveis para isto. Porém somente entender os tempos não é suficiente para melhorar o desempenho do processo, é muito importante que sejam estudados os tempos e métodos, bem como os movimentos necessários para a realização do produto ou serviço de uma organização.

O estudo de tempos segundo Peinado e Graeml (2007), aborda técnicas que submetem a uma detalhada análise cada operação de uma dada tarefa, com o objetivo de eliminar qualquer elemento desnecessário à operação e determinar o melhor e mais eficiente método para executá-la.

\section{Metodologia}

Realizou-se um estudo prático da confecção de cestas decorativas com paletas de picolé. Para a produção das cestas foram necessários paletas de picolé e cola instantânea.

A cesta é formada por 19 paletas, sendo distribuídas em 6 paletas para a parte traseira, 6 paletas para a lateral direita, 6 paletas para a lateral esquerda e uma paleta para frontal, sendo recordada em partes: a menor parte tem $2,5 \mathrm{~cm}$ na horizontal superior e $1,5 \mathrm{~cm}$ na horizontal inferior, a paleta intermediária são $6 \mathrm{~cm}$ na horizontal superior e $5 \mathrm{~cm}$ na horizontal inferior, e para a maior paleta são $9 \mathrm{~cm}$ na horizontal superior e $7,7 \mathrm{~cm}$ na horizontal inferior.

Para a formação da parte traseira foram utilizadas duas paletas na vertical sendo ligadas por 4 paletas sendo coladas nas seguintes dimensões: $0 \mathrm{~cm}, 3,8 \mathrm{~cm}, 7,6 \mathrm{~cm}$ e $11,5 \mathrm{~cm}$ sendo necessário a formação de uma angulação entre as paletas horizontais, para a formação de um losango.

Para a formação das laterais utilizam-se duas paletas na vertical sendo coladas por 4 paletas de $8 \mathrm{~cm}$ cada, sendo coladas nas seguintes dimensões: $0 \mathrm{~cm}, 3,8 \mathrm{~cm}, 7,6 \mathrm{~cm}$ e $11,5 \mathrm{~cm}$.

Para a confecção das peças foi necessário juntar a parte traseira com as laterais colando nas mesmas dimensões anteriormente citadas, como pode ser visto no apêndice I. 
Inicialmente a atividade foi dividida por etapas, sendo dividida em 4 etapas, montagem da parte traseira, montagem da lateral direita, montagem da lateral esquerda e montagem da peça por completo.

Para a obtenção das melhorias, inicialmente foi preciso realizar a atividade sem nenhuma metodologia utilizada, então cada operador marcava as medidas no palito e seguia para montagem.

\subsection{Planejamento do processo de padronização}

O método de Poka-Yoke é dividido em 4 modalidades, para evitar erros de prevenção, detecção, valor fixo e etapas. O método utilizado foi o de prevenção, onde foi criado um dispositivo a prova de falha, no caso um molde para determinar o local exato onde o material deve ser colocado para montagem do produto.

Primeiro foram coletados dados da produção sem o molde, onde cada operador montava as peças de maneira que achasse melhor. Após essa etapa foram descritos os problemas, a partir deles iniciou-se o processo de padronização do processo, através de brainstorm com os operadores e o medidor dos tempos para chegar até o método do Poka-Yoke preventivo. Após a implementação da melhoria os tempos foram cronometrados novamente e feita uma análise comparativa com os tempos anteriores.

Para o processo de padronização, foram realizados os cálculos para a obtenção da angulação entre as paletas verticais da parte traseira. Também com a ajuda de um transferidor foi possível perceber que se formava um ângulo de $70^{\circ}$ como na figura 2 - dimensões da base.

Com isso foi possível desenvolver um mecanismo a prova de falhas, que consiste na obtenção de moldes, com as especificações métricas do produto, que auxiliariam na hora do encaixe das paletas em seus devidos lugares, dispensando a perca de tempo na medição dos pontos e no ajustamento. 
Figura 1 - Dimensões das laterais

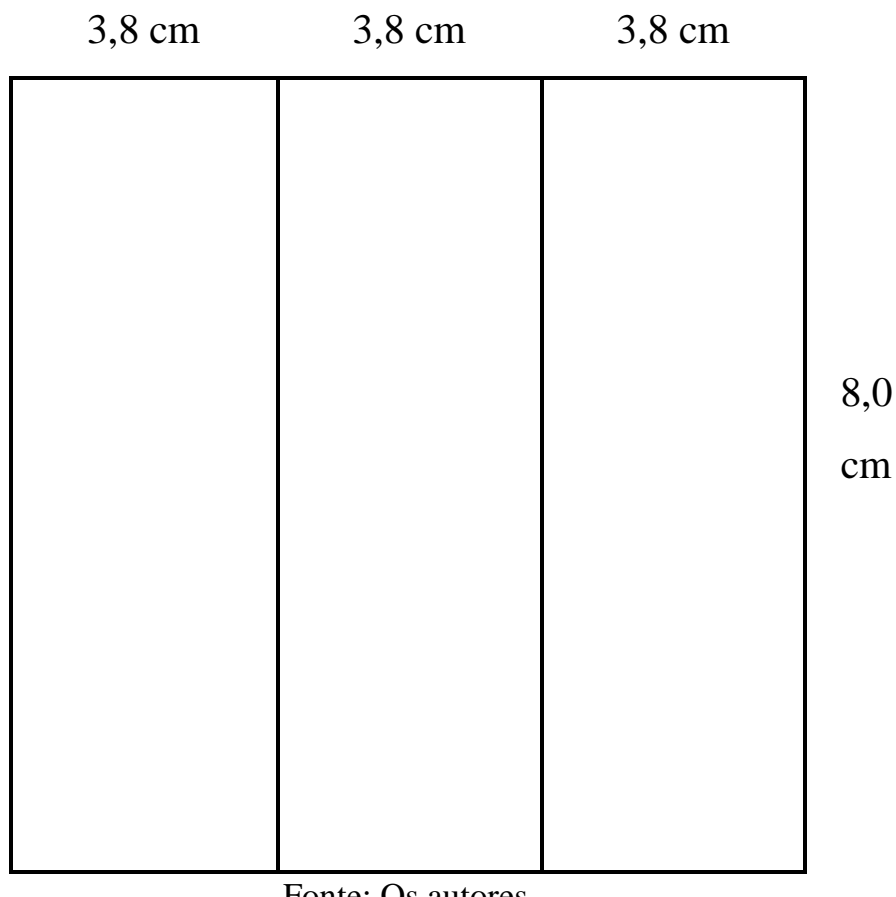

Fonte: Os autores

Figura 2 - Dimensões da base

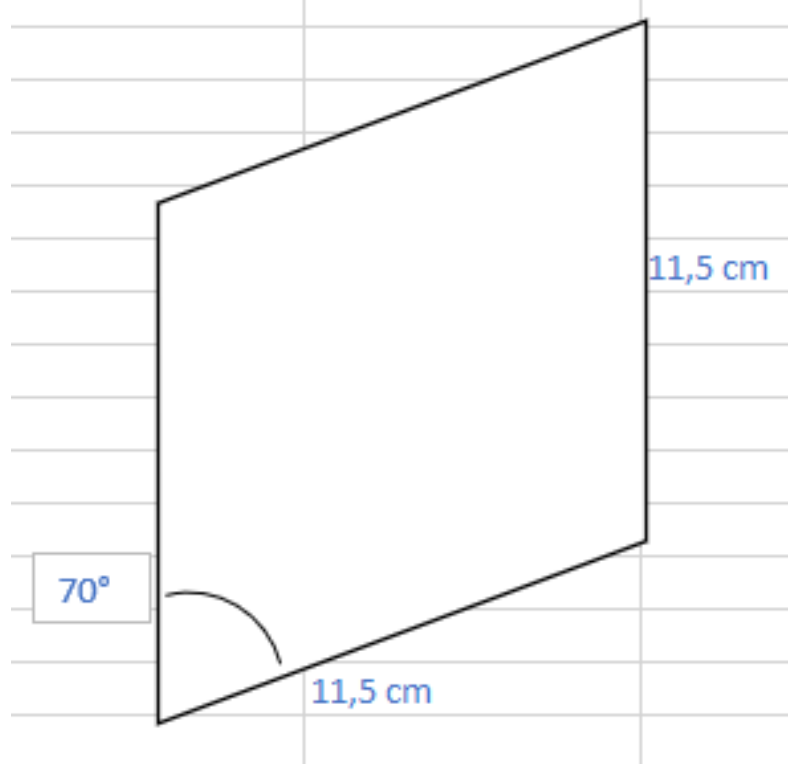

Fonte: Os autores

Os mecanismos foram feitos de isopor e pedaços de paletas de picolé que seriam descartados do corte, evitando que o material deslize ou fique mal colocado no processo de colagem. 


\section{Resultados e discussões}

\subsection{Medição De Tempos}

Os tempos foram medidos de acordo com a realização da atividade por cada operador. Operador 1 e operador 2 fazem as laterais do produto, que são iguais; operador 3 faz a base; e, operador 4, junta a base das laterais e a frontal. Logo, as laterais e a base são feitas simultaneamente para o quarto operador juntá-las, finalizando o produto.

Tabela 1 - Tempos.

\begin{tabular}{|c|c|c|c|c|c|}
\hline tempos & $\begin{array}{c}\text { Operador } \\
1\end{array}$ & $\begin{array}{c}\text { Operador } \\
2\end{array}$ & $\begin{array}{c}\text { Operador } \\
3\end{array}$ & $\begin{array}{c}\text { Operador } \\
4\end{array}$ & média(t) \\
\hline t1 & $00: 01: 57$ & $00: 02: 21$ & $00: 02: 02$ & $00: 02: 55$ & $00: 02: 19$ \\
\hline t2 & $00: 01: 56$ & $00: 02: 17$ & $00: 01: 50$ & $00: 02: 32$ & $00: 02: 09$ \\
\hline t3 & $00: 01: 28$ & $00: 01: 44$ & $00: 01: 43$ & $00: 02: 11$ & $00: 01: 47$ \\
\hline t4 & $00: 01: 14$ & $00: 01: 20$ & $00: 01: 29$ & $00: 02: 09$ & $00: 01: 33$ \\
\hline t5 & $00: 01: 11$ & $00: 01: 13$ & $00: 01: 15$ & $00: 01: 53$ & $00: 01: 23$ \\
\hline média(p) & $00: 01: 33$ & $00: 01: 47$ & $00: 01: 40$ & $00: 02: 20$ & \\
\hline
\end{tabular}

Fonte: Os autores.

\subsection{Cálculo dos tempos}

\subsubsection{Tempo normal}

Escolheu-se o “operador 1" para realização dos cálculos dos tempos, pois possui a menor média dos tempos para realização da atividade. Antes do cálculo do tempo normal precisou-se definir a eficiência do grupo segundo:

$$
E f=\frac{F e z}{\text { Pode Fazer }}
$$

Onde o tempo do "operador 1" foi substituído no denominador (pode fazer), pois o mesmo tinha conseguido realizar a atividade no menor tempo, e o tempo do "operador 2", "operador 3", e "operador 4" foram substituídos no numerador (fez). Este cálculo foi realizado apenas uma vez para cada operador. 


\begin{tabular}{|c|c|c|}
\hline & $\begin{array}{l}\text { Tempo } \\
\text { médio }\end{array}$ & Eficiência \\
\hline Operador 1 & $00: 01: 33$ & $100,00 \%$ \\
\hline Operador 2 & 00:01:47 & $87 \%$ \\
\hline Operador 3 & 00:01:40 & $93,00 \%$ \\
\hline \multirow[t]{2}{*}{ Operador 4} & 00:02:20 & $66,43 \%$ \\
\hline & Média & $86,59 \%$ \\
\hline \multicolumn{3}{|c|}{ Fonte: Os autores. } \\
\hline \multicolumn{3}{|c|}{$E f=86,59 \%$} \\
\hline
\end{tabular}

Logo, o tempo normal com base no operador mais rápido se deu através de:

\section{$\mathrm{TN}=\mathrm{TR} \times \mathrm{Ef}$}

Onde, o TR que é a média das cronometragens, foi substituído pela média dos tempos cronometrado do "operador 1".

$$
\begin{gathered}
\mathrm{TN}=00: 01: 33 \times 0,8659 \\
\mathrm{TN}=93 \times 0,8659 \\
\mathrm{TN}=80,5287 \text { segundos }
\end{gathered}
$$

\subsubsection{Tempo padrão}

$$
\mathrm{TP}=\mathrm{TN} \times \mathrm{FT}
$$

$\mathrm{FT}=$ Fator de tolerância $=(1+\mathrm{T})$, T é um valor percentual tabelado.

Foi calculado o fator de tolerância que a empresa disponibilizou para seus operadores realizarem suas necessidades fisiológicas, tolerância para alívio das fadigas provenientes da prática contínua e sistematizada do trabalho. A tabela abaixo mostra como pode se avaliar o fator de tolerância de fadiga. 
Tabela 3 - Avaliação do fator de tolerância de fadiga utilizado na prática

\begin{tabular}{|c|c|c|c|c|c|c|c|}
\hline \multicolumn{8}{|c|}{ AVALIACĀO DO FATOR DE TOLERĀNCIA } \\
\hline \multicolumn{4}{|c|}{ Tabela 1} & \multicolumn{2}{|c|}{ Tabela 2} & \multicolumn{2}{|c|}{ Tabela 3} \\
\hline \multicolumn{4}{|l|}{ Nivel de esforco } & \multirow{2}{*}{\multicolumn{2}{|c|}{$\begin{array}{l}\text { Condiçoes ambi- } \\
\text { entats }\end{array}$}} & \multirow{2}{*}{\multicolumn{2}{|c|}{ Monotonia do trabalho }} \\
\hline \multirow{2}{*}{ NIVEL } & Mental & Visual & Fisico & & & & \\
\hline & $\%$ & $\%$ & $\%$ & Tipo & $\%$ & Ciclo (minuto) & $\%$ \\
\hline Muito leve & 1 & 1 & 3 & $\mathrm{~A}$ & 0 & atê 0.5 & 5 \\
\hline Leve & 2 & 2 & 5 & $\mathrm{~B}$ & 2 & de 0,6 a 1,0 & 4 \\
\hline Médio & 4 & 4 & 8 & C & 4 & de 1.1 a 1.5 & 3 \\
\hline Pesado & 7 & 7 & 12 & D & 6 & \multirow{2}{*}{\multicolumn{2}{|c|}{$\begin{array}{c}\text { acima de } 1,5 ; \text { utiltzar a } \\
\text { Tabela } 1 \\
\end{array}$}} \\
\hline Muito pesado & 10 & 10 & 18 & $\mathrm{E}$ & 8 & & \\
\hline \multicolumn{8}{|c|}{$\begin{array}{l}\text { - Aplicar para cada elemento da operação } \\
\text { - Somar os percentuais dos três tipos de esforços } \\
\text { - Adicionar à soma dos esforços, o percentual da tabela } 2 \\
\text { - O uso da tabela } 1 \text { exclui o uso da tabela } 3 \\
\end{array}$} \\
\hline Tabela 2 & Tipo A & \multicolumn{6}{|c|}{$\begin{array}{l}\text { - Sem ruídos, poetra ou umidade. Calor ou frio normais. } \\
\text { - Iluminaçao e ventilacâo adequadas } \\
\text { - Sem riscos de acidentes ou doenças profissionais } \\
\text { - Ruidoso, muita poeira ou umidade. Excesso de calor ou frio artifl- } \\
\text { clats. } \\
\text { - Iluminaçâo e ventilação péssimas } \\
\text { - Razoável risco de acidentes e doencas profisstonais }\end{array}$} \\
\hline Tabela 3 & $\begin{array}{l}\text { - Uthlizar } \\
\text { - Somar } \\
\text { - O uso } \\
\end{array}$ & $\begin{array}{l}\text { para as o } \\
\text { à avalfaçâ } \\
\text { da tabela } 3\end{array}$ & $\begin{array}{l}\text { raçốcs a } \\
\text { o percer } \\
\text { xclut o } 1 \\
\end{array}$ & $\begin{array}{l}\text { amente n } \\
\text { 1al da tal } \\
\text { da tabe }\end{array}$ & $\begin{array}{l}\text { Stonas } \\
2\end{array}$ & sem csforços & \\
\hline
\end{tabular}

Fonte: Peinado; Graeml (2007)

Levando em consideração que as operações são monótonas, além das condições ambientais serem insuficientes no fator de iluminação e ventilação, as condições ambientais são do tipo B, e a monotonia do trabalho é de até 0,5 minuto, temos:

$\mathrm{T}=2 \%+5 \%=7 \%$

$\mathrm{FT}=1+\mathrm{T}=1,07$

$$
\begin{gathered}
\mathrm{TP}=80,5287 \times 1,07 \\
\mathrm{TP}=86,166 \text { segundos }
\end{gathered}
$$

\subsection{Curva de aprendizagem}

Para cada operador, de acordo com a Tabela 1 - Tempos, calculou-se os dados para a construção da curva de aprendizagem como segue:

$$
t_{n}=t_{1} \times n^{-b} \quad b=\frac{-\ln p}{\ln 2} \quad p=\frac{t_{2}}{t_{1}}
$$


Tabela 4 - Cálculos para curva de aprendizagem.

\begin{tabular}{|c|c|c|c|c|}
\hline $\begin{array}{c}\text { Curva de } \\
\text { Aprendizagem }\end{array}$ & $\begin{array}{c}\text { Operador } \\
1\end{array}$ & $\begin{array}{c}\text { Operador } \\
\text { Operador } \\
\text { Operador }\end{array}$ & $\begin{array}{c}\text { Op } \\
4\end{array}$ & \\
\hline t1 & $00: 01: 57$ & $00: 02: 21$ & $00: 02: 02$ & $00: 02: 55$ \\
\hline t2 & $00: 01: 56$ & $00: 02: 17$ & $00: 01: 50$ & $00: 02: 32$ \\
\hline t3 & $00: 01: 56$ & $00: 02: 15$ & $00: 01: 44$ & $00: 02: 20$ \\
\hline t4 & $00: 01: 55$ & $00: 02: 13$ & $00: 01: 39$ & $00: 02: 12$ \\
\hline t5 & $00: 01: 55$ & $00: 02: 12$ & $00: 01: 36$ & $00: 02: 06$ \\
\hline
\end{tabular}

Fonte: Os autores

Gráfico 1 - Curva de Aprendizagem

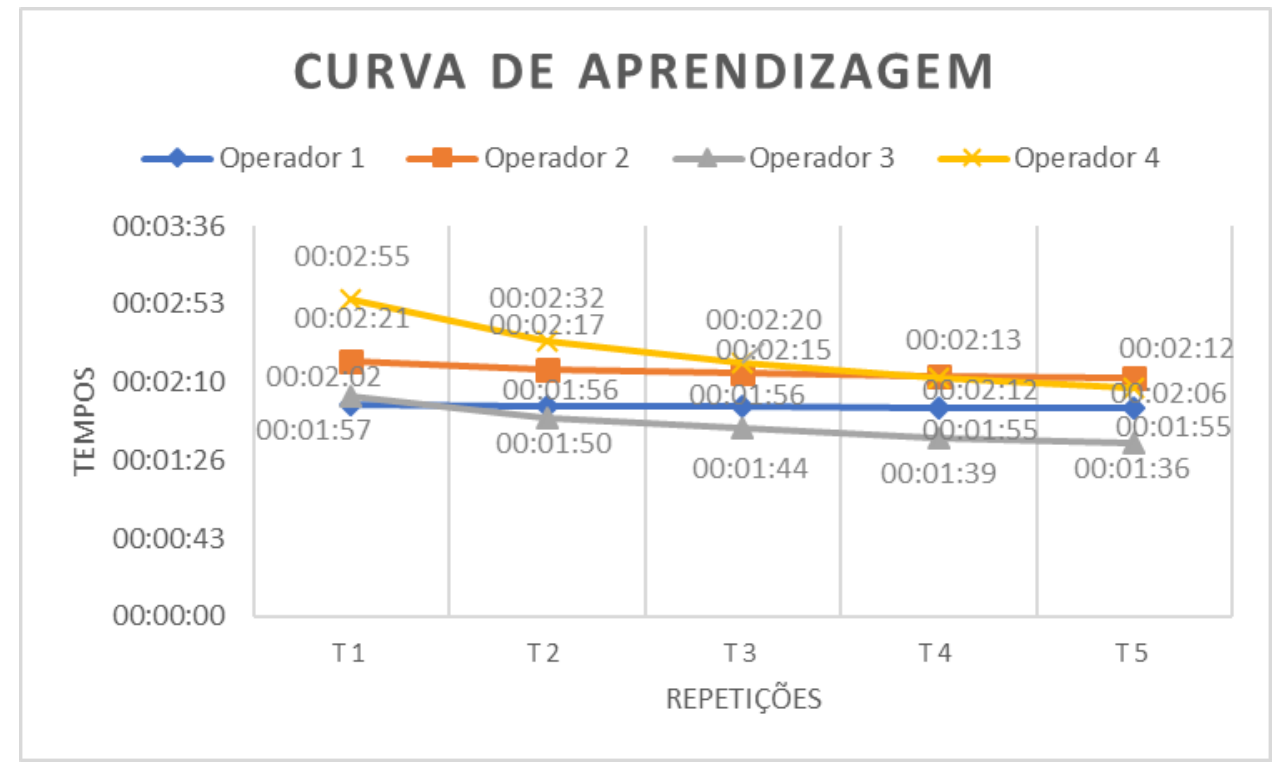

Fonte: Os autores

\subsection{Cálculo do número de postos de trabalho}

Levando em consideração que em época de festas, como natal e final de ano, a procura por itens de decoração aumentam, foi considerada uma demanda de 150 peças a serem atendidas em $1 \mathrm{~h}$ de trabalho.

$$
N=\frac{t \times D}{h \times E \text { ficiềncia }}
$$

$\mathrm{D}=$ Demanda;

$\mathrm{h}=$ carga horária trabalhada; 
t: $\quad$ tn = quantidade mínima de recursos;

$\mathrm{TP}=$ quantidade máxima de recursos (tempo).

$$
\mathrm{TP}=86,166
$$

$\mathrm{h}=1$ hora $=3.600$ segundos

$$
N=\frac{86,166 \times 150}{3.600 \times 0,8659}
$$

$$
N=4,146
$$

Logo foram necessários, no mínimo, 5 operários para suprir a demanda estipulada.

\subsection{Nova medição de tempos}

A partir do processo de padronização, com a utilização de formas para realizar cada etapa da construção do produto, obteve-se novos tempos de medição como segue na tabela:

Tabela 5 - Novos Tempos

\begin{tabular}{|c|c|c|c|c|c|}
\hline tempos & Operador & Operador & Operador & Operador & média(t) \\
& 1 & 2 & 3 & 4 & \\
\hline t1 & $00: 00: 43$ & $00: 00: 49$ & $00: 00: 28$ & $00: 01: 31$ & $00: 00: 53$ \\
\hline t2 & $00: 00: 42$ & $00: 00: 47$ & $00: 00: 24$ & $00: 01: 20$ & $00: 00: 48$ \\
\hline t3 & $00: 00: 42$ & $00: 00: 47$ & $00: 00: 23$ & $00: 01: 05$ & $00: 00: 44$ \\
\hline t4 & $00: 00: 39$ & $00: 00: 46$ & $00: 00: 21$ & $00: 01: 00$ & $00: 00: 42$ \\
\hline t5 & $00: 00: 38$ & $00: 00: 46$ & $00: 00: 21$ & $00: 00: 58$ & $00: 00: 41$ \\
\hline média(p) & $00: 00: 41$ & $00: 00: 47$ & $00: 00: 23$ & $00: 01: 11$ & \\
\hline
\end{tabular}

Fonte: Os autores

\subsection{Novo cálculo dos tempos}

\subsubsection{Tempo normal}

Diferentemente da primeira análise, o "operador 3" possui a menor média de tempos para realização da atividade, logo foi considerado o tempo base para realização dos cálculos. Antes do cálculo do tempo normal precisou-se definir a eficiência do grupo: 


\begin{tabular}{|c|c|c|}
\multicolumn{2}{|c}{ Tabela 6 - Nova Eficiência } \\
\cline { 2 - 3 } & $\begin{array}{c}\text { Tempo } \\
\text { médio }\end{array}$ & Eficiência \\
\hline Operador 1 & $00: 00: 41$ & $56,10 \%$ \\
\hline Operador 2 & $00: 00: 47$ & $49 \%$ \\
\hline Operador 3 & $00: 00: 23$ & $100,00 \%$ \\
\hline Operador 4 & $00: 01: 11$ & $32,39 \%$ \\
\hline & Média & $59,36 \%$ \\
\cline { 2 - 3 } & &
\end{tabular}

Fonte: Os autores

$$
E f=59,36 \%
$$

Logo, o tempo normal com base no operador mais rápido se dá através de:

$$
T N=T R \times E f
$$

TR = média dos tempos do "operador 3".

$$
\begin{aligned}
& T N=00: 00: 23 \times 0,5936 \\
& T N=13,6528 \text { segundos }
\end{aligned}
$$

\subsubsection{Tempo padrão}

$$
T P=T N \times F T
$$

$\mathrm{FT}=$ Fator de tolerância $=(1+\mathrm{T})$, T é um valor percentual tabelado.

Da mesma forma que foi definido a tolerância na primeira análise, temos:

$\mathrm{T}=2 \%+5 \%=7 \%$

$\mathrm{FT}=1+\mathrm{T}=1,07$

$$
\begin{gathered}
T P=13,6528 \times 1,07 \\
T P=14,6085 \text { segundos }
\end{gathered}
$$




\subsection{Nova curva de aprendizagem}

Tabela 6 - Cálculos para nova curva de aprendizagem

\begin{tabular}{|c|c|c|c|c|}
\hline $\begin{array}{c}\text { Curva de } \\
\text { Aprendizagem }\end{array}$ & $\begin{array}{c}\text { Operador } \\
1\end{array}$ & $\begin{array}{c}\text { Operador } \\
\text { Operador }\end{array}$ & $\begin{array}{c}\text { Operador } \\
3\end{array}$ & 4 \\
\hline t1 & $00: 00: 43$ & $00: 00: 49$ & $00: 00: 28$ & $00: 01: 31$ \\
\hline t2 & $00: 00: 42$ & $00: 00: 47$ & $00: 00: 24$ & $00: 01: 20$ \\
\hline t3 & $00: 00: 41$ & $00: 00: 46$ & $00: 00: 22$ & $00: 01: 14$ \\
\hline t4 & $00: 00: 41$ & $00: 00: 45$ & $00: 00: 21$ & $00: 01: 10$ \\
\hline t5 & $00: 00: 41$ & $00: 00: 44$ & $00: 00: 20$ & $00: 01: 07$ \\
\hline
\end{tabular}

Fonte: Os autores

Gráfico 2 - Nova curva de aprendizagem

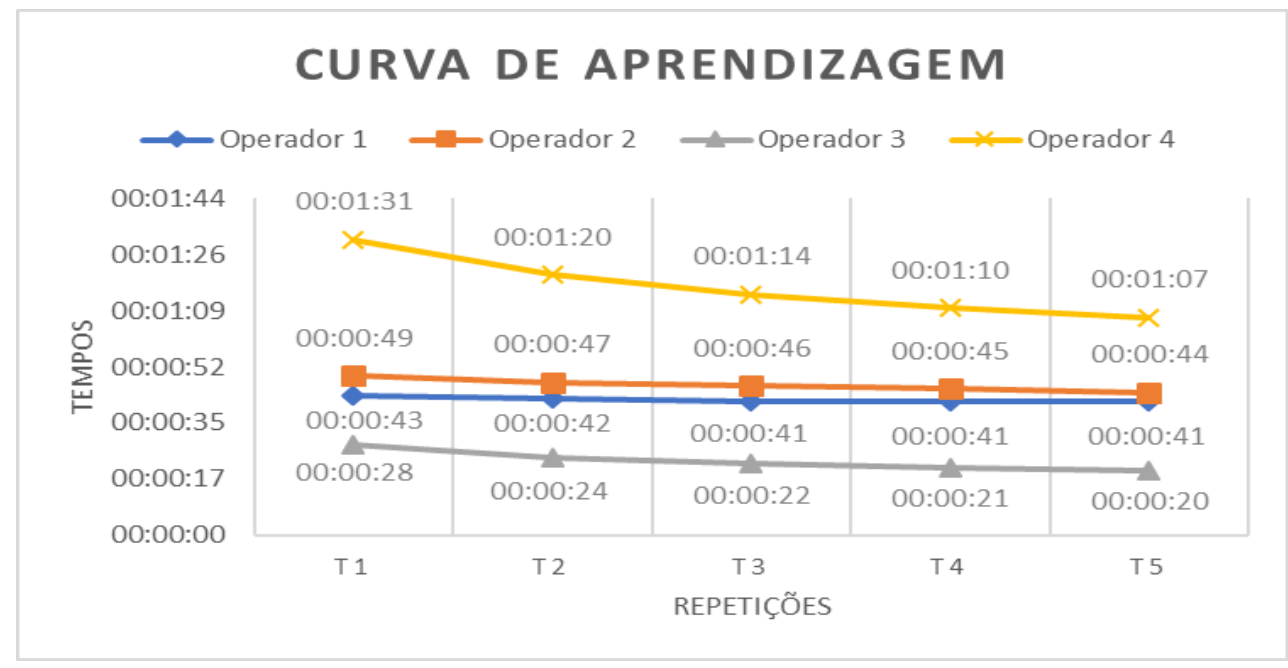

Fonte: Os autores

4.8. Novo cálculo do número de postos de trabalho

$$
\mathrm{N}=(\mathrm{t} \times \mathrm{D}) /(\mathrm{h} \times \text { Eficiência })
$$

$\mathrm{D}=$ Demanda;

$\mathrm{h}=$ carga horária trabalhada; 
t: $\quad$ tn = quantidade mínima de recursos;

$\mathrm{TP}$ = quantidade máxima de recursos (tempo).

$$
\mathrm{TP}=14,6085 \text { segundos }
$$

$\mathrm{H}=1$ hora $=3.600$ segundos

$$
\mathrm{N}=(14,6085 \times 150) /(3.600 \times 0,5936)
$$

$$
\mathrm{N}=1,025
$$

Logo são necessários no mínimo 2 operários para suprir a demanda estipulada.

\section{Conclusão}

Com o estudo das aulas explicativas, além de pesquisas em artigos, livros e revistas, o estudo dos tempos de produção, dos mecanismos a prova de falha, com o processo de padronização além do processo de melhoria contínua leva o grupo a se aproximarem das práticas reais e lidar com as falhas e imprevistos durante o processo de produção, despertando a visão do futuro engenheiro de produção a buscar métodos viáveis de melhorias de acordo com os problemas.

De início observou-se que muito tempo era voltado para a marcação das medidas e que esse processo, que pode ser feito de maneira mecanizada, estava sendo repetitivo e demorado. Usando-se a padronização de medidas e ângulos, além da barreira que impedirá o material a deslizar na colagem, reduziria o tempo de maneira significativa, e de acordo com os cálculos pode-se observar que o número de operários para atender a demanda passa de 5 para 2, menos da metade da mão de obra para produzir a mesma quantidade de demanda no mesmo tempo de trabalho.

Assim para análises e estudos futuros, pode-se considerar reavaliar todo o processo levando em consideração os novos tempos e números de funcionários, com uma nova distribuição de tarefas e focando no operário que ficou mais distante das médias dos demais para melhorias. 


\section{REFERÊNCIAS}

PERIARD, Gustavo. Tudo Sobre a Administração Científica de Taylor. Disponível em: < http://www.sobreadministracao.com/tudo-sobre-a-administracao-cientifica-de-taylor/> Acesso em: 30 de novembro de 2019.

TAYLOR, F (1903) - Shop Management.

BARNES, Ralph Mosser. Estudo De Movimentos e de Tempos: Projeto e Medida do Trabalho. 6 ed. São Paulo: Edgar Blücher, 1977.

GHINATO, P. (1996) - Sistema Toyota de Produção, mais do que simplesmente just-in-time. EDUCS, Caxias do Sul.

OHNO, T. (1997) - O Sistema Toyota de Produção; Além da produção em larga escala. Porto Alegre, Bookman.

MARTINS, H. A. Estudo sobre os conceitos da autonomação e aplicação de PFMEA para auxílio na implementação de sistemas à prova de erro. Trabalho de graduação - Escola de Engenharia de São Carlos, Universidade de São Paulo, São Carlos, 2009.

SHIMBUN, N. K. Poka-yoke: improving product quality by preventing defects. Portland, MA: Productivity Press, 1988.

NOGUEIRA, L. J. M. Melhoria da Qualidade através de Sistemas Poka-Yoke. 2010. Disponível em: <https://repositorio-aberto.up.pt/bittream/10216/59614/1/000141304.pdf>. Acesso em: 10 de jan. 2020.

SHINGO S. 1996. O sistema Toyota de produção, do ponto de vista da engenharia de produção. Porto Alegre: Artemed.

POSAJEK, R.B. 1999. Poka-Yoke and Zero Waste. Environ. Quality Management. 2: 91-97.

PEINADO, J.; GRAEM, A. R. (2007) - Administração da Produção: Operações Industriais e de Serviço. Unicemp, Curitiba - PR. 


\section{APÊNDICES}

Apêndice I - Montagem da cesta

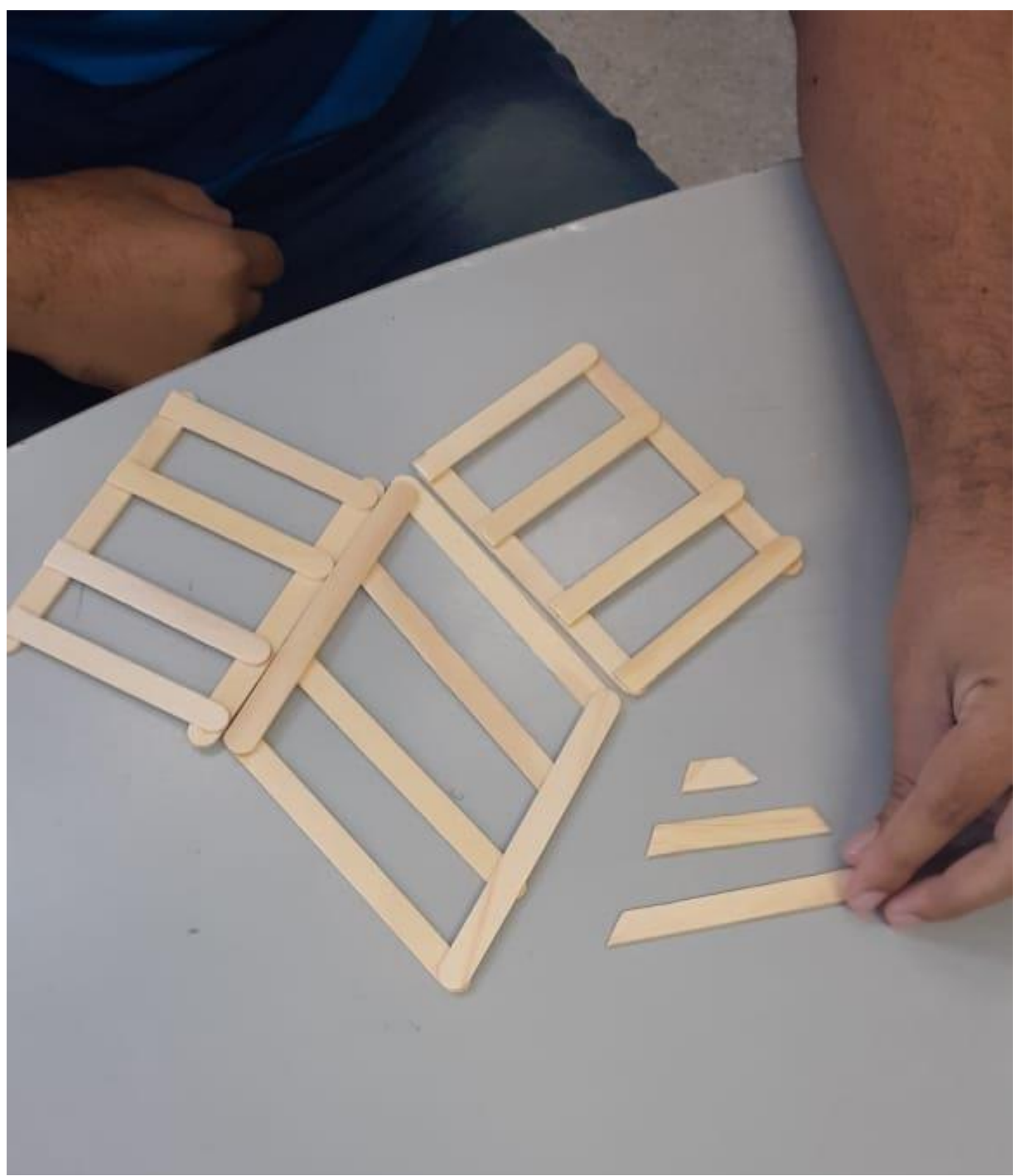

